Paidéia, 2002, 12(23), 163-175

\title{
INTELIGÊNCIA COMO CONSTRUCTO E COMO PROCESSO: SUMÁRIO DAS PESQUISAS AO LONGO DO TEMPO ${ }^{1}$
}

\author{
Franco Lo Presti Seminerio ${ }^{2}$ \\ Universidade Federal do Rio de Janeiro
}

RESUMO: Partindo da conceituação culturalmente corrente de inteligência, das implicações em termos da recente teoria da mente e das decorrências éticas e políticas, visa-se, neste artigo, tracejar o percurso das investigações científicas nesta área. Inicialmente destaca-se a tentativa de avaliar a idade mental e o constructo de QI, na Europa e nos Estados Unidos. Avalia-se, em seguida, o esforço dos fatorialistas para aprofundar o processo intelectual, a partir de seus determinismos. A busca de Spearman de um fator geral, através de um cálculo estatístico - equação tetrádica - e a ampliação desta teoria, bifatorial, para uma concepção hierárquica. A objeção metodológica de Thurstone e a criação do método centróide e da teoria multifatorial. A crítica epistemológica de Guilford ao modelo radicalmente empirista e a descrição antecipada de três dimensões básicas envolvendo cinco categorias de operações, seis de produtos e quatro de conteúdos (no modelo original). A posição anterior de Thorndike e a visão ambientalista multimodal, centrada na aprendizagem. A visão racionalista e universalista da Epistemologia Genética e as decorrências pedagógicas como autonomia radical no desenvolvimento ontogenético. Críticas. A visão social de Vigotzky e a contribuição da psicologia soviética. A aproximação da lingüística e da cognição. A contribuição de Bruner ao longo de quatro etapas. $O$ grande debate inatismo ambientalismo e implicações político-sociais. O advento da metacognição, teoria da teoria e teoria da mente e as pesquisas de diagnóstico e de intervenção psicopedagógica. O papel do desenvolvimento intelectual para uma política igualitária de emancipação.

Palavras-Chave: Psicologia Cognitiva, Inteligência, Educação, História da Psicologia.

\section{INTELLIGENCE AS A CONSTRUCT AND AS A PROCESS: A SUMMARY OF RESEARCHES ALONG THE TIME}

ABSTRACT: The aim of this article is to draw up a sketch of the scientific researches about intelligence, starting from the cultural concept, and the recent mind's theory and on the ethic and political consequences. Firstly the endeavor of evaluating the mental age and IQ in Europe and the Unites States is detached. Following the attempt of the factorialists to go deeper into the intellectual process, throughout its foundations. The search of the general factor by Spearman through the tetraic equation and the enlargement of this bifactorial theory bound for a hierachical conception is discussed. Thurstone's methodological objection and the creation of the centroid method led to a multifactorial theory. Guilford's epistemological criticism to the prior radical empirical model, led him to describe in advance three dimensions of intelligence, including five categories of operations six of products and four of contents - in the original model. The Thorndike' s former position and the enviromentalist multimodal point of view, founded on the learning, is discussed as well as the universal and rational position of Genetic Epistemology with the pedagogic consequences like the radical autonomy of the ontogenetic development. The social perspective of Vigotzky and the contributions of the sovietic psychology are concerned. The closeness of linguists and psychologists is analyzed and the Bruner's contributions along four stages. The great debate between inherits and the environmentalism and its social and political implications. The emergence of the metacogniton as well the theory's theory, the mind's theory, and the new kind of diagnosis and pedagogical intervention. The meaning of the intellectual development for a politics of social emancipation.

Key-Words: Cognitive Psychology, Intelligence, Education, and History of Psychology

\footnotetext{
' Artigo recebido para publicação em julho de 2002; aceito em agosto de 2002

${ }^{2}$ Endereço para correspondência: Franco Lo Presti Seminerio, Universidade Federal do Rio de Janeiro, Instituto de Psicologia, Curso de Pós-Graduação em psicologia, Av. Pasteur, 250, Fundos, Pavilhão Nilton Campos, $2^{\circ}$ andar, Praia Vermelha, Rio de Janeiro, RJ, Cep 22290-240, E-mail pospsicologia@psycho.ufrj.br
} 


\section{Franco Lo Presti Seminerio}

Uma das maiores iniqüidades sociais, tão perversa quanto a má distribuição de rendas é, em nosso entender, a má distribuição da inteligência, entre as classes sociais. Inúmeras vezes já emitimos esta opinião e, para evitar equívocos, cabe preliminarmente tornar claro este ponto de vista. Não se trata de supor que a maioria dos membros das classes desfavorecidas tenha um potencial intelectual inferior ao dos membros das classes privilegiadas. Como veremos em seguida, defendemos não haver diferenças inatas quanto ao potencial intelectual. $\mathrm{O}$ que pesa, para a maioria dos membros das classes de baixa renda, é a reduzida margem de oportunidades para desenvolver esse potencial, em condições de igualdade com os que provem de classes ou situações abastadas. E esta falta de oportunidades, somada ao baixo poder econômico dos membros desta classe, passa a ser também responsável por uma restrita margem de chances de ascensão social, criando assim um autêntico círculo vicioso. Estamos, neste caso, perante um problema que não é só técnico-científico, mas também social e político e principalmente ético. Neste sentido, cabe, mais uma vez, destacar o papel do psicólogo, do educador e, em geral, do intelectual, perante tal situação. Como enfatizou Gramsci (1949) não cabe às massas e sim aos intelectuais planejar a promover transformações sociais.

Inteligência, na opinião da maioria é um termo e um conceito óbvio, principalmente quando se trata de avaliar pessoas ou atitudes - inclusive as próprias. Torna-se claro, neste caso, que se trata de um juízo metacognitivo. No entender de Noël (1992) a avaliação de pessoas, condutas e tarefas constituem sempre uma reflexão de segunda ordem, ou seja uma reflexão sobre o ato de refletir, próprio ou alheio.

A dificuldade surge quando ser trata de formular comparações específicas, tal como estabelecer se cabe considerar mais inteligente um grande poeta ou um cientista ou uma pessoa bem sucedida na vida, nas realizações pragmáticas do dia a dia e até nos negócios. Tentar resolver o impasse admitindo formas distintas de inteligência, como aptidões independentes, tem se tornado, com frequiência uma solução de bom senso aparente, mas, na maioria dos casos, superficial, uma vez que desloca o problema inicial para inúmeras facetas que tendem a desdobrá-lo ilimitadamente. Este aliás tem sido um dos fios condutores de uma vertente ainda inacabada da investigação. Um segmento que após as sofisticadas pesquisas dos fatorialistas do começo do século XX (Spearman, Burt, Thurstone, Guilford, principalmente) voltou, recentemente, para soluções muito mais simples, até certo ponto óbvias, nas quais transparece o sentido da experiência socialmente acumulada, como no caso das Inteligências Múltiplas (Gardner,1995)

Uma avaliação retrospectiva nos permite registrar que o conceito - e o termo - de inteligência, em psicologia, não é tão antigo como outros aspectos e conceitos do psiquismo. Para Guilford (1967) devese a Spencer (1895) a introdução do termo em psicologia. Ainda, segundo o mesmo autor deve-se a Burt (1955) a suposição que o termo proceda da intelligentia de Cícero e que a concepção unitária da inteligência, designada como monárquico remonte ao Século XV (p.11).

As recentes investigações sobre teoria da teoria e teoria da mente puseram em evidência que a psicologia científica não passa de uma sofisticação e ampliação de conceitos e termos existentes, provavelmente desde épocas pré-históricas. A primeira poderia ser entendida como um prolongamento da concepção piagetiana de pseudonecessidade.Com este termo acreditava Piaget que deveria ser identificada a necessidade de formular explicações sem fundamento, característica da criança pré-operatória. Trata-se de uma exigência cognitiva primordial do ser humano, como necessidade de entender, em termos de conexões lógicas, o que se oferece à experiência. $\mathrm{Na}$ falta de dados surgem conclusões inadequadas, instigadas por esta pressão mental, a fim de corresponder à necessidade explicativa. O resultado, neste caso, não seria o alcance de uma necessidade lógica e real, mas apenas de uma pseudonecessidade.

Da teoria da teoria à teoria da mente a passo é breve, o que hoje leva a supor que se trate de uma das mais remotas atividades cognitivas do ser humano, ainda que seu estudo venha sendo desenvolvido há apenas três décadas. De fato, admitindo-se que haja uma necessidade natural, quase instintiva, para explicar o que se oferece à experiência, o que mais deve impressionar, em qualquer circunstância, é entender o comportamento 
do outro e de si mesmo. Aceitando a tese Fodor (1984) que qualquer conduta é resultado de algum desejo acoplado a alguma crença, é óbvio que a compreensão da presença em si e nos demais de desejos e crenças passe a ser uma razão primordial para explicar a conduta relacional e social. É o que justifica o crescente aumento de pesquisas nesta área. Recentemente vem se buscando qual poderia ser a idade em que uma criança sabe claramente que o outro -notadamente os pais tem desejos e crenças que podem, inclusive opor-se aos deles. Nesta linha vem se delineando a idade de três a quatro anos como ponto de transição significativo para este objetivo. O que mereceria passar a ser considerado como um ato fundamental na organização da inteligência infantil. Ademais uma pesquisa de Premack e Woodruff (1978) encontrou vestígios claros de teoria da mente no chimpanzé. Entendemos que qualquer pessoa pode avaliar o quanto outros animais domésticos conseguem manipular seus donos ou manifestar sinais de culpa perante o que entendem que possa tê-los desagradado. O que já envolve alguma forma de compreensão dos desejos e crenças alheios.

Contrariamente ao operacionismo associacionista do Behaviorismo, estas recentes investigações apontam para a presença de atos e condutas impregnados de significação desde níveis infra-humanos, o que há anos tentamos mostrar através de nossas investigações sobre designação (Seminerio, 1995).

Nesta linha de indagações, cabe ampliar a suposição de ocorrerem avaliações espontâneas em pessoas de qualquer nível e até em crianças não apenas quanto à compreensão de haver crenças, desejos e memória nos demais e em si próprio, mas também quanto à atitude, praticamente universal, de julgar constantemente a sensatez de qualquer ato, próprio ou alheio, o que poderia equivaler a admitir, em termos de teoria da mente a percepção de uma conduta que poderia corresponder à avaliação da inteligência em termos operacionais de seus resultados. Embora pareça óbvio que deva existir também desde a pré-história esta atitude metacognitiva de avaliar a competência própria e dos demais, são ainda escassos, até o momento, dados de pesquisas que visem corroborar esta hipótese.
É certo que as primeiras colocações tidas como científicas no campo da inteligência apontam para uma fronteira bem tênue entre a investigação guiada por alguma teoria e a sistematização de noçōes de bom senso. Quando tentarmos avaliar a concepção de Binet e Simon (1905) certamente esbarraremos nesta constatação. Propor problemas verbais a crianças, para derivar um suposto cálculo de idade mental pode parecer até ingênuo, em nossos dias; e no entanto, no seu tempo, muitos acreditaram tratarse de uma solução excelente, para fundar procedimentos científicos para a psicologia cognitiva, no seu nascedouro. Talvez o que pode ter parecido superficial tenha sido a metodologia, ou seja definir como conduta apropriada para cada idade a freqüência bruta de soluções apuradas em cada faixa etária. Hoje, evidentemente, outros cálculos e processos deveriam ser promovidos.

A Universidade de Stanford assumiu o desafio de superar esses óbices, através de um longo e árduo sistema de investigações, que ainda hoje representa um modelo metodológico de primeira ordem. Referimo-nos, evidentemente, as padronizações realizadas por Terman em 1916 e principalmente em 1937. Nesses trabalhos, porém, além da idade mental, outro constructo havia sido introduzido: o QI quociente de inteligência - cujos ônus e bônus, todavia não se devem mais a Binet e sim a Stern (1912/1971) que o propôs poucos meses após o falecimento de Binet. Mais uma vez volta-se ao senso comum - ao dividir o escore apurado no teste, transformado em idade mental, pela idade cronológica de uma criança. $O$ escasso rigor destas medidas, que deveriam fornecer os qualia, ou seja os enunciados protocolares para elaborar a investigação, suscitou a reação de Spearman (1927) que, desde 1904 apresentou a sua proposta de fator geral. Ao longo de muitos anos de uma penosa pesquisa, alcançaria uma solução fatorialista, após submeter cerca de 30.000 participantes a uma longa e meticulosa investigação

Apesar do esforço empreendido, a fim de ultrapassar a visão simplista e um tanto ingênuo de Binet, que definia a inteligência como "o que o meu teste mede", a busca de um fundamento teórico e técnico para definir a inteligência humana por este caminho esbarrou novamente num simplismo 


\section{Franco Lo Presti Seminerio}

tautológico, de vez que a inteligência passava a identificar-se com o fator geral ou $G$. Ademais o caminho empirista da indução arriscava cair no equívoco do psicologismo: partir dos fatos para as normas. Ou seja, tentar explicar universais necessários - em função de registros contingentes. Como mostraremos todas as teorias fatorialistas acabaram trilhando sob este aspecto o mesmo caminho. A metodologia de Spearman, a pesar de minuciosa e trabalhosa, principalmente quando os recursos tecnológicos ainda eram limitados, também pecava por um simplismo excessivo: ao reunir um grande número de habilidades elementares a partir das quais tentava extrair, através de correlações simples, um fator geral comum a todas através da conhecida equação tetrádica obtida pelo cruzamento das correlações em cada conjunto de quatro habilidades consideradas e comparadas em pares. $\mathrm{A}$ fórmula estabelecida ( $\mathrm{rab} \times \mathrm{rcd}=\mathrm{rac} \times \mathrm{rbd}$ ) permitia inferir a existência de uma relação sistemática entre as quatro habilidades. Note-se que este cruzamento de correlações não oferece esse resultado a não ser quando estiverem em jogo competências intelectuais. À medida que esta relação vinha-se repetindo na maior parte dos conjuntos de habilidades, concluiu Spearman que deveria haver em qualquer capacidade intelectual umfator geral, supostamente biológico e hereditário e um fator específico (fator s) próprio de cada habilidade, que poderia inclusive ser adquirido.

$\mathrm{Na}$ tentativa de explicar teoricamente o fundamento cognitivo do fator geral, Spearman o descreveu em termos de três leis noegenéticas - isto é leis explicativas da gênese, isto é da origem de qualquer ato inteligente - (1) compreensão e clareza no ato e no momento de focalizar a experiência; 2 ) edução de relações; 3 ) edução de correlatos. Note-se o neologismo edução para mostrar que não se trataria nem de dedução nem de indução: seria a competência para extrair relações ou correlações dos conteúdos da experiência- o que não deixa, evidentemente de representar uma atitude indutiva. $O$ caráter empirista torna-se evidente também nesta concepção da atividade inteligente, entendida como uma conduta eminentemente receptiva e passiva - exceto quanto à terceira lei noegenética, que não implica todavia qualquer ato criativo ou inovador.
Ao admitir o binômio fator $G \times$ fatores $s$ - que conferiu à sua perspectiva a denominação de teoria bifatorial - Spearman também se opunha a aceitar fatores overlapping isto é competências intermediárias. acima dos fatores específicos e abaixo do fator geral, tal como a capacidade matemática, verbal e outras. Ao que parece, ao supor a hereditariadade biológica do fator geral, não haveria como admitir outros fatores universais em atividades dependentes de criações da cultura. Só nos últimos anos de sua vida acabou se rendendo à evidência estatisticamente apurada - desses fatores.

Burt (1949) - figura polêmica e hoje contestada - em contraposição à teoria bifatorial criara um modelo hierárquico no qual admitia uma bifurcação inicial, colocando de um lado um fator geral e do outro um fator prático; abaixo haveria nova bifurcação em fatores de um segundo nível (associações),e, em seguida, de um terceiro (percepções) e, finalmente, de um quarto (sensações). Coube a Vernon (1950) estabelecer uma feição mais ajustada desta árvore, colocando acima de tudo um fator geral $(g)$, abaixo do qual propôs dois fatores de grupo maiores ou seja dois grupos de competências: de um lado os fatores $v$-ed - ou verbo-educacionais ligados à aprendizagem notadamente quando veiculada pela linguagem - e de outro os fatores $k: m$ - cinestésico-motores - ligados à ação e a condutas executivas. Num terceiro nível haveria fatores de grupo menores reunindo diversos fatores especificos, os quais comporiam o $4^{\circ}$ nível dessa árvore.

Thurstone $(1938 ; 1948)$, engenheiro e psicólogo levantou sua crítica metodológica ao trabalho de Spearman. Ao comparar habilidades em grupos de quatro, só poderia aflorar um único fator geral, isto é comum às quatro habilidades consideradas. Bem diferente poderia ser o resultado correlacionando simultaneamente um número muito maior de habilidades. Elaborou para esse fim um método específico: o método centróide, fundado num procedimento estatístico voltado para encontrar os fatores ortogonais num espaço apto a projetar todos os eixos das correlações a partir de um único ponto central - derivando daqui o nome do método, que ainda hoje representa um modelo fundamental da análise fatorial. As correlações assim projetadas iriam - numa imagem figurada - aparecer como tantas 
constelações num firmamento. A partir das habilidades correspondentes às abcissas e às ordenadas de cada eixo poderia se interpretar a competência envolvida em cada uma dessas supostas correlações. Imaginou encontrar por este caminho as habilidades primárias (primary metal abilities P.M.A.sigla das primeiras baterias de testes fundados neste critério). Descreveu por este caminho diversos fatores primários porque ortogonais, treze dos quais foram realçados, entre os quais oito tornaram-se clássicos: dois nas áreas verbal - W (word) fluência verbal e V (verbal) raciocínio verbal - dois na área abstrato-simbólica: R raciocínio abstrato e $\mathrm{N}$ fator numérico - um único na área espacial: $\mathrm{S}$ fator espacial - um na área de percepção (vigilante): $\mathrm{P}$ (perception) fator de atenção concentrada - um na área de memória - M - e um na área da inteligência psicomotora - Mo. Esta teoria passou a ser conhecida como multifatorial

Na posição de Thurstone. não ficou claramente definido o caráter inato ou adquirido das habilidades mentais primárias. Até que ponto poderia constituir funções inatas da mente humana? Poderia parecer implícito pela própria denominação; mas na falta de uma definição peremptória poderia sè admitir outra alternativa: além do inatismo dessas competências, supostamente universais, poderia ocorrer uma modalidade de aquisição do potencial de cada fator, através da experiência individual e social notadamente familiar. Mais adiante voltaremos a discutir essa problemática.

Guilford (1967) apontou uma impropriedade metodológica no trabalho de Thurstone: à medida que este colocava em suas verificações um soma de dados heterogêneos, os resultados iriam agregar sem um critério lógico pertinente informações supostamente conclusivas. Assim Thurstone teria encontrado um fator verbal e um fator espacial que representariam conteúdos da atividade mental e, paralelamente, um fator abstrato, ou seja um processo dessa atividade. Para superar esta dificuldade abandonou o método indutivo e elaborou um modelo com 120 fatores obtidos pela conjugação da cinco processos ou categorias de operação (cognição - isto é captação e decodificação da informação; memória; produção divergente; produção convergente; avaliação); seis categorias de produtos (unidades, classes, relações, sistemas, transformações, implicações) e quatro categorias de conteúdos (figural, simbólico, semântico e comportamental). Os conjuntos dessas categorias representariam assim as três dimensões básicas da inteligência que o autor representou através da figura de um cubo, no qual a área superior representaria as operações, a vertical os produtos e a base os conteúdos. Pelas conexões decorrentes haveria 120 fatores representados por outros tantos pequenos cubos inseridos no cubo maior, combinando em cada caso as três dimensões. Haveria portanto no primeiro cubinho superior a cognição de unidades figurais, no segundo a memória de unidades figurais e assim sucessivamente.

Note-se que Guilford abandonou praticamente a aleatoriedade do método indutivo na sua investigação, para atender à racionalidade de uma descrição previamente planejada. Minuciosos cálculos estatísticos acompanharam as suas pesquisa. A pesar destes cuidados esta teoria, levada a campo para verificação, não encontrou a esperada comprovação. Tampouco foi possível operacionalizar um grande número de fatores previamente definidos pela mera interseção das dimensões programadas. Todavia sua contribuição foi essencial para impulsionar as investigações sobre criatividade, a partir da concepção de produção divergente. Ou seja, a situação em que a resposta não depende mais de uma escolha proposta ou insinuada ao sujeito e sim. de um ato de invenção, isto é de criação de uma resposta nova e inusitada.

Anterior a todas estas investigações fatorialistas, a posição de Thorndike (1927) não oferece qualquer dúvida ou ambigüidade entre a perspectiva inatista e a ambientalista. Trata-se da teoria multimodal que assume, consistentemente, o seu caráter exógeno: não há como buscar na mente as estruturas ou os fatores primários da cognição, pois estes decorrem do que foi estruturado a nível coletivo pela sociedade e pela cultura que organizam os modos de aprendizagem para aos indivíduos. Através da indução podem se levantar até supostos fatores criados pelas práticas da sociedade, como a "habilidade para o galanteio". Por este caminho havia chegado a supor uma inteligência social distinta da inteligência propriamente dita. 


\section{Franco Lo Presti Seminerio}

Ao longo de trinta anos de magistério nessa área, tentamos promover uma reavaliação dessas divergências, através de uma síntese inspirada numa categorização de E. Mira y Lopez (Seminerio, 1997). Este pesquisador definiu três modos de comportamento: verbal, quando operado sobre a linguagem natural e discursiva; abstrato quando codificado em linguagem simbólica, e espacial quando desenvolvido a partir de dados concretos ou materiais.

Nosso intuito era estabelecer uma reavaliação epistemológica de todas essas investigações de base empírica, apta a ser utilizada em termos práticos, no diagnóstico psicológico. Concluímos pela pertinência de reagrupar os diversos fatores num modelo integrado.

Entendemos que ofator $G$ independentemente de ser inato poderia decorrer de uma competência experiencial cumulativa, enquanto em cada uma das três áreas poderia haver um determinante algorítmico, automátizável e uma aptidão heurística. No primeiro caso haveria a fluência verbal, a habilidade de cálculo e dimensionamento do espaço. Na vertente heurística destacamos o raciocínio verbal, incluindo a habilidade dialética, o raciocínio abstrato, quer indutivo e quer principalmente dedutivo e a percepção do movimento, abarcando o raciocínio mecânico. Quanto à memória e à atenção, como competências retentiva e de focalização vigilante, ambas deveriam apresentar, em função da aprendizagem, níveis diferenciados de potencial para cada uma das três áreas (verbal, abstrata e espacial).

Bem diferente das investigações conduzidas principalmente nos países anglo-saxônicos, o projeto da Epistemologia Genética, programa criado por J.Piaget, em 1953, como prosseguimento de suas investigações iniciadas na década de '20. Buscava soluções não apenas para os problemas da psicologia cognitiva. Numa ótica abrangente tentava abarcar num sistema unificado, além da teoria do conhecimento humano e infra-humano, todo o conjunto das ciências, reatando-as num sistema capaz de explicar uma gênese recíproca, o conhecido círculo das ciências. Nesta indagação percebera a existência de dois segmentos do saber humano: um representado pelas ciências formais, com alto grau de sofisticação e, em alguns aspectos, de acabamento (notadamente a lógica e a matemática); outro constituído por ciências empíricas em ascensão (física, biologia, psicologia e sociologia). Como seria possível entender a marcha no terreno destas últimas, rumo às abstrações das primeiras? Em outras palavras como poderia se explicar a evolução da mente humana, a partir das informações obtidas através do desenvolvimento biológico, psicológico - e social até alcançar um tipo de conhecimento muito anterior: o da matemática e da lógica? Indiscutivelmente parecia existir um hiato. E o programa da Epistemologia Genética aceitou o desafio de tentar preenchê-lo.

Neste contexto a inteligência deixa de ser entendida como um fator, ou até mesmo como um processo independente: representa o nível de equilíbrio global alcançado pela mente de cada indivíduo. Desde a racionalidade - e eficácia - de seus gestos e demais atos motores, até o nível de suas abstrações e clareza de julgamento. Ao supor a transição ao longo de cada período do seu desenvolvimento, admite o alcance de patamares específicos, próprios de cada etapa: esta sequiência evolutiva é comum a todos. Decorre desta concepção a crítica mais contundente à sua doutrina: como pode haver um percurso evolutivo comum, sem um programa geneticamente fixado? A resposta de Piaget apela para a lógica do processo globalmente considerado. Assim - exemplificando - o aprendizado da medida linear, levará, necessariamente, qualquer um ao aprendizado subseqüente, o das medidas de superfície, bidimensionais (áreas) e estas, por sua vez ao das medidas tridimensionais (volume). Coloca-se assim o peso do que énecessário, em sentido lógico, acima do que é seqüencial, em sentido evolutivo. Até mesmo porque a evolução obedece a um padrão de racionalidade. $O$ homem - e qualquer ser vivo - não é uma deriva natural como para Varela (1989). Ao contrário, todos os padrões do universo obedecem a uma lógica obrigatória. "A lógica é a axiomática da razão, da qual a psicologia da inteligência é a ciência experimental"(Piaget, 1947). Costumamos defender que, sob este ângulo, Piaget aplica, nas ciências naturais um postulado de Frege (1974): a lógica - e a matemática - envolvem as leis das leis, que nenhuma instância, natural ou sobrenatural poderia 
criar ou produzir, mas somente obedecer, por estarem embutidas em qualquer tipo de realidade ou de possibilidade. É por esta razão que Frege pode ser considerado o Platão de nosso tempo: em vez das idéias que Platão imaginava representarem os modelos dos objetos, como semântica do real, são as leis da lógica que constituem a própria sintaxe de qualquer tipo de realidade, inerentes a tudo o que é ou pode ser.

O plano unificador das ciências, proposto e pesquisado pela Epistemologia Genética (Piaget, 1957) passa assim a entendê-las como um prolongamento necessário do conhecimento, ao longo de uma extensão paralela ao processo da evolução de todos os seres vivos. Não há solução de continuidade entre o desenvolvimento e construção da mente infantil e a atividade que o cientista consegue realizar como dublagem desse vasto processo.

A psicologia do desenvolvimento tal como foi concebida por Piaget insere-se dentro deste amplo quadro, de modo consistente. Ademais não se esgota na existência individual. Entre os períodos descritos por sua teoria, o primeiro - o período sensório motor, que abarca os primeiros 24 meses da existência de cada ser humano - é talvez o que obteve maiores comprovações transculturais. Foi o que Piaget estudou e descreveu através de uma metodologia clínica, representada por observações sistemáticas realizadas sobre a conduta dos seus três filhos.

O período subsequiente, o pré-operatório havia sido objeto das primeiras investigações piagetianas, ainda na década de '20. Sua importância teórica funda-se no surgimento da primeira dublagem mental da conduta, inicialmente só executiva e consumatória. $E$ neste período que se estabelece a capacidade conceitual e simbólica. Todavia é no período seguinte, das operações concretas, que se define a primeira etapa da conduta lógica. O conceito de operação é fundamental nesse momento: a representação da ação rígida e pouco articulada do período pré-operatório assume a flexibilidade que a torna reversível. Assim a ação outrora só executada passa a ser não apenas representada, mas também mentalmente elaborada, invertida ou anulada mediante uma tomada de consciência que em si já representa um prolegômeno, ainda escassamente consciente, de metacognição. Um novo salto de escala ocorre no quarto período, o das operações formais, em que se torna possível operar não apenas sobre as ações, mas inclusive sobre as respectivas coordenações e suas representações ao nível de conceitos e de linguagem representativa. Emerge assim o pensamento hipotético dedutivo. Ocorre portanto uma dublagem da dublagem da ação. $O$ adolescente torna-se capaz de atuar sobre a logica formal, dissociada de conteúdos materiais. No entanto estudos críticos (Vieira, 1987) apontaram que a emergência desta competência não constitui uma regra, na adolescência. Pelo contrário só consegue ser atingida através de estudos especializados de lógica e matemáticos.

Os passos ulteriores passam a ser os do raciocínio científico. Acreditava Piaget que todos esses saltos ocorreriam de modo autônomo, através de sucessivas equilibrações majorantes.

Esta á razão pela qual propõe um grau de liberdade radical para o educando. Basta aguardar que ele desenvolva sua própria construção interna, a cada passo. Esta não deixará de ocorrer, desde que a criança disponha dos recursos necessários para promover, por si mesma, o seu teste progressivo da realidade. A cada momento poderá efetuar nova equilibração (majorante) construindo assim, sucessivamente as suas estruturas. Este tipo de aprendizagem (lato sensu) não pode ser ensinado: cada ser humano poderá adquiri-lo somente a partir de suas ações à medida que estas o levem a se reequilibrar, através de contínuas assimilações $\mathrm{e}$ consequientes acomodações.

A posição aqui adotada opõe-se abertamente a tal perspectiva - que já tentamos expor com alguns detalhes (Seminerio, 1996) - por entender que todo conhecimento passa necessariamente pela relação com o outro, mediante transição de modelos, inspirando-nos na tese de Bandura (1977) e, em parte, de Vigotzky (1989).

A linha adotada por este último, pese à sua morte prematura, oferece um exemplo criativo das possibilidades de desenvolvimento de um postulado de base marxista, qual seja a construção do ser humano a partir de determinismos sociais. Os dois processos básicos da constituição mental de qualquer ser humano, o pensamento e a linguagem, mesmo 


\section{Franco Lo Presti Seminerio}

sendo independentes, embora paralelos, são sempre tributários do que é oferecido pelo ambiente, incluindo neste a formação educacional, quer vertical, quer horizontal. Quanto à linguagem, estende-se a concepção do segundo sistema de sinais de I.P.Pavlov. O ostracismo temporário lançado na União Soviética sobre a figura de Vigotzky, por motivos políticos, não conseguiu ofuscar sua imagem, naquele país. Na realidade foi o mundo ocidental a desconhecer, durante muitos anos o valor e o sentido de sua contribuição. Em sua perspectiva, desde o nascimento o ser humano é moldado pelo ambiente que transfunde nele estruturas básicas e idéias fundamentais para pensar, além do sistema de sinais necessários para compor a linguagem. A criança, portanto, não é inicialmente egocêntrica como defendia Piaget - : ao contrário, desde o começo é socializada uma vez que tudo recebe, e em tudo depende do meio em que se encontra. Somente ao alcançar a idade de 6 ou 7 anos torna-se capaz de interiorizar o que recebeu e elaborar criticamente o que lhe é ou the foi oferecido. Vigotzky entende a conduta egocêntrica como o processo de interiorização que a criança se torna capaz de efetuar nessa idade. Parece-nos não haver conflito entre as duas posições pois que ambos referem-se a processos distintos: Piaget entende o egocentrismo como a impossibilidade inicial de qualquer criança penetrar na percepção e na compreensão do outro. Não consegue de fato descentrar da sua percepção. Para Vigotzky a socialização envolve receptividade e assimilação inicial - e permanente - de qualquer pessoa do que o meio lhe oferece; e o egocentrismo a incorporação e elaboração interior do que foi recebido, o que só ocorre a partir de certa idade.

Dentro da psicologia soviética outras duas linhas tiveram um desenvolvimento privilegiado: a neuropsicologia de A.R. Luria - que muito contribuiu para um ajuste no mapeamento cerebral, graças ao trabalho realizado sobre vítimas de ferimentos cerebrais, durante a segunda guerra mundial e a preocupação lingüística e educacional (Davydov, 1981; Galperin, 1981;Leontiev, 1972; Luria, 1971).

O desenvolvimento da lingüística iria promover também nos Estados Unidos uma renovação profunda dos rumos da psicologia cognitiva. Por volta da metade do Século XX um grupo de psicólogos e um outro de lingüístas perceberam que, em suas áreas estavam penetrando num campo limítrofe, não apenas em sentido de interseção, mas principalmente como constituição de um objeto novo e comum de investigação. Alguns encontros tiveram um papel decisivo para esta guinada. Em 1956 houve dois eventos de uma importância significativa: o Seminário sobre teoria da informação do M.I.T. e o Encontro de Darmuth, onde surgiu a Inteligência Artificial. Em 1960 Bruner e Miller criaram, em Harvard, o Center for Cognitive Studies, visando firmar e estender esse campo de investigações. Nesse mesmo ano a publicação de Plans and Structures of Behavior (Miller \& cols, 1960) representou a introdução da perspectiva. cognitiva no Behaviorismo. Abriam-se assim as portas do movimento cognitivista.

A conceituação e a medida do significado havia sido descartada pelo Behaviorismo em sua fase inicial. Coube a Osgood (1962) enfrentar o desafio de sua introdução dentro desse contexto teórico. A teoria mediacional por ele proposta escuda-se neste processo como direcionamento básico da conduta. Para efetuar essa mensuração introduziu um conceito e um procedimento engenhoso: a semântica diferencial de uso corrente, em nossos dias não apenas na linguística - como diferencial semântico - mas também nas avaliações de sistemas conotativos, principalmente em psicofísica.

A contribuição de Bruner, na realidade, já vinha se destacando desde a década de ' 40 . Pesquisador polimorfo e criativo desenvolveu um trabalho diversificado, ao longo de mais de sessenta anos, podendo-se distinguir pelo menos quatro fases - para alguns seis - de sua atuação. Num primeiro momento participou da criação do movimento $\mathrm{New}$ Look in Perception, que tentava reavaliar o estudo da percepção e dos fundamentos da teoria gestaltista, à luz da contribuição psicanalítica, principalmente da Psicopatologia da vida Cotidiana (Freud, 1974). Uma investigação sobre o teste de Rorschach levara a entender o quanto a percepção - e conseqüentemente a cognição como um todo - é impregnada pelas influências emocionais (Bruner, 1948). Uma segunda fase o levaria a aprofundar o estudo do pensamento (Bruner, Goodnow \& Austin, 1956), principalmente em termos de estratégias e 
processos. Na terceira fase acentua-se o interesse pela atividade pedagógica e pelo desenvolvimento cognitivo humano. Duas importantes perspectivas teóricas emergem neste período. Por um lado a conhecida teoria dos três níveis de atividade humana. Contrapondo-se à tese dos períodos de Piaget, propôs três formas de ação, geneticamente estabelecidas na espécie, que vão surgindo de acordo com o programa de maturação e superpondo-se progressivamente. Inicialmente o comportamento ativo envolve a competência cognitiva primordial, explicitada diretamente sobre a realidade. Em seguida surge uma modalidade de representação paralela, e analógica, a conduta icônica capaz de produzir imagens, esquemas visuais - ou mentais - aptos a traduzir a ação num autêntico mapeamento. Finalmente a conduta simbólica permite reportar o conteúdo mental - e a respectiva comunicação - em termos de linguagem e conceitos. Reconhece portanto três formas de inteligências, sempre presentes, em cada ser humano. Além da importância pedagógica destas três modalidades de atividade e representação, destaca Bruner (1973) o significado hierarquizado de certas disciplinas, áreas e métodos de estudo correspondentes. Em particular o da matemática, verdadeira matriz do desenvolvimento intelectual, por representar em si a mais autêntica expressão da metacognição. Neste aspecto tornou-se Bruner o precursor e o pioneiro deste atual campo de investigações.

Em épocas mais recentes seu foco de interesse voltou-se para o estudo, a pesquisa e a teorização sobre linguagem (Bruner, 1991). A diferença de Piaget, destaca essencialmente a importância da relação interpessoal como foco primário da captação do sistema de sinais sobre o qual assenta a construção da linguagem e o fundamento da comunicação humana.

A partir da década de ' 50 foi se acirrando uma polêmica aparentemente teórica, mas com profundas implicações sociais, éticas e, principalmente políticas. Seria a inteligência o. produto de uma faculdade hereditária, à guisa de um "dom", ou decorreria da experiência oferecida pelo meio, principalmente familiar? A primeira hipótese, durante muito tempo, parecia corresponder a um critério de bom senso, e até certo ponto talvez tenha sido aceita como óbvia pela maioria - ressalvado o papel da aprendizagem, realçado, entre os psicólogos, especialmente pelos behavioristas. A discussão havia-se tornado mais clara em 1935 , quando a União Soviética havia proibido uso da "psicotécnica", considerada uma forma burguesa de assegurar a perpetuação das classes superiores no poder. Todavia foi só a partir das décadas de ' 50 e ' 60 que o problema foi encarado em sua real amplitude. $O$ conceito de meritocracia (Young, 1958) tornou nítida a ótica segundo a qual as diferenças sociais poderiam ser encaradas como diferenças biológicas. No entanto segundo Eysenck (1971) a maioria dos especialistas estaria defendendo ainda, naquela época, a tese ambientalista, tanto que a posição inatista de Jensen (1969) foi recebida com hostilidade, chegando a gerar um famoso trocadilho.

Em 1640 Cornelius Jansen publicara o "De Agostino" - condenado pela Igreja como herético em 1653 - pelo qual o acesso ao céu depenđeria de predestinação. Sua doutrina passou a ser conhecida como Jansenismo. Eysenck (ibid.) aponta que a posição de Jensen que propunha a hereditariedade como determinante da capacidade intelectual, foi considerada herética por uma grande parte dos cientistas sociais e denominada Jensenismo através de um artigo do New York Times. Evidentemente não se tratava mais do acesso ao reino do céu, através da disponibilidade da graça, mas da predestinação ao poder na terra, pela disponibilidade da inteligência. Duas implicações tornavam-se óbvias, a partir desta tese: por um lado a diferença entre raças; por outro a perpetuação das classes e das diferenças sociais, poderiam decorrer de um determinismo biológico.

Em pleno fervor desta polêmica, foi solicitada aos dois maiores defensores das posições antagônicas -Eysenck e Kamin (1982) - a redação de um livro onde cada um apresentasse sua tese sem ter acesso ao manuscrito do competidor, o que redundou na publicação de $O$ Grande Debate sobre a Inteligência.

Eysenck defendeu principalmente as diferenças entre raças. Cabe observar que não teve dificuldade para se defender da acusação de estar adotando uma posição nazista, a partir do seu próprio histórico. Nascera em Berlim em 1916. Em 1934, revoltado com a ascensão de Hịtler ao poder 


\section{Franco Lo Presti Seminerio}

abandonou a Alemanha. Após um período de estudos literários na França foi para a Inglaterra, onde se aprofundou em psicologia, tendo como mestre Burt. Durante a segunda guerra mundial fez propaganda, em alemão contra a Alemanha, através da rádio britânica.

A defesa das diferenças raciais e da hereditariedade intelectual, fundou-se nas teses controversas de Burt, - que se suspeita tenha forjado dados para obter as suas provas. De acordo com os resultados apresentados mostrou Eysenck que, em primeiro lugar, nessa escala de progressão do nível mental, estariam os Judeus - situados acima de um desvio-padrão além da média universal; em seguida os Chineses e os Japoneses, depois os brancos e por último os negros. Esclareceu sobejamente que não se trataria de uma escala absoluta, mas essencialmente estatística. Admitia a existência de superdotados negros, mas para cada superdotado negro haveria diversos brancos, principalmente judeus.

Para os que percebiam o peso da culpa de submeter as classes de mais baixa renda aos trabalhos mais penosos, tornava-se mais fácil aceitar a fatalidade desta submissão.

Em sustento dessa posição ergueram-se os defensores do inatismo, isto é da crença em diferenças inatas quanto ao potencial intelectual. Todavia, o mais importante paladino do inatismo em psicologia, N. Chomsky não compartilhou essa opinião: Defendeu a universalidade das funções - que seriam realmente inatas. Assim como os pássaros têm asas para voar, os homens têm recursos para falar e pensar. No entanto as diferenças de potencial quanto ao uso dessas funções decorreriam de fatores sociais.

A postura ambientalista de Kamin prendeuse principalmente à opressão social que impedia aos negros e aos membros de classes dominadas a ascensão social e o acesso a um sistema educacional favorável. É nesta ótica que se alinha a postura mencionada e um pouco anterior de Chomsky (1972): num contundente artigo contra o uso dos testes, atacou com veemência a imoralidade dessa forma de opressão, revestida de uma máscara e de uma aparência científica.

Kamin e Chomsky entenderam que esta seria a plataforma ideológica para defender as diferenças inatas. De fato, a partir desta ideologia, em qualquer regime, inclusive numa sociedade igualitária, os mais aptos assumiriam o poder e ainda iriam gerar descendentes destinados a assumi-lo. Neste caso, a distribuição dos seres humanos em classes sociais deixaria de ser um problema político para tornar-se uma exigência biológica.

A demonstração do inatismo por parte de Eysenck fundava-se em dois suportes: por um lado as afirmações de C. Burt, sempre mais desacreditado, quer pelas elevadas e quase impossíveis correlações, acima de .90 - entre gêmios criados em separado, ou entre pais e filhos reais, comparados com filhos adotivos - quer pela possível invenção de sujeitos nunca localizados. Por outro lado Eysenck aceitava sem crítica os resultados de testes de QI, sempre mais contestados em nossos dias.

$\mathrm{O}$ ambientalismo de Kamin partiu desses prováveis erros metodológicos - cujas falhas tentou realçar com provas reais - e do ostensivo interesse das classes dominantes em justificar uma opressão social eticamente incômoda. Neste contexto desaparece o mito do superdotado que passa a ser concebido como um produto essencialmente social e, principalmente, familiar.

Após quase meio século de indagações e verificações em campo, Gardner (1995) tentou avaliar a extensão de trabalho realizado até então. Apesar do minucioso cuidado metodológico empreendido pelos antecessores, acreditou que todo esse trabalho escapava à realidade prática, tornando-se ineficiente para atingir a individualidade de cada um. Inicialmente propôs um novo alinhamento das ciências cognitivas, apto a reunir numa Nova Ciência da Mente junto com a psicologia cognitiva, a lógica, a matemática, a lingüística, a antropologia e a neuropsicologia. Estabelecia-se uma clivagem entre este conjunto e outros campos da psicologia. Em seguida tentou definir áreas distintas e diferenciadas da inteligência. Rejeitou as definições anteriores porque fundadas num critério operacional (escores dos testes, principalmente). Abandonou a ótica dos resultados para definir as aptidões intelectuais, para privilegiar a "capacidade de resolver problemas ou elaborar produtos" (Gardner, 1995). Descreveu assim sete formas distintas e independentes de inteligência. Duas de caráter eminentemente personalógico - a 
inteligência intrapessoal e a intepessoal. Duas voltadas para o domínio dos conteúdos cognitivos mais abrangentes - linguagem, e lógica-matemática e três envolvendo habilidades bastante específicas: a inteligência musical, a corporal-cinestésica e a espacial. Não se tratava mais de recorrer a cálculos estatísticos e sim à avaliação lógica das fronteiras de cada processo. O objetivo declarado era eminentemente prático, pedagógico, guiado mais pelo bom senso do que pela pesquisa.

Partindo de uma reavaliação da perspectiva de Descartes Fodor (1987) postulou uma concepção modular da mente, no qual o eixo horizontal permite diferenciar as faculdades captadas intuitivamente, tal como "memória, imaginação, atenção, sensibilidade e assim por diante". Estas constituiriam a versão mais familiar. O eixo vertical envolve propensões e competências, como por exemplo a musical. $O$ autor reporta-se a frenologia de Gall, adaptada às concepções atuais. Decorre assim a existência de uma memória musical, de uma memória matemática e assim por diante, em face da interseção dos dois eixos.

A abordagem modular de Sternberg (2000) destaca o caráter hierátquico dos módulos e é tributária dos avanços realizados na área da inteligência artificial.

A pesquisa experimental de Hart (1965) sobre o Feeling of Knowing (FOK) introduziu "paradigmas experimentais para examinar as relações entre índices objetivos e subjetivos de conhecimento" (Koriat, 1996). Esta pesquisa, resultado da tese de doutoramento do autor, pode ser considerada o ponto de partida da metacognição uma das mais recentes e significativas áreas da psicologia cognitiva. Efetivamente ocorreu uma ruptura do paradigma behaviorista, pois que a investigação do sentimento de conhecer não podia mais ser conduzida em terceira pessoa - dentro dos cânones do comportamentismo clássico - precisando ser desenvolvida em primeira pessoa. Analogamente as derivações respectivas, já referidas, como a teoria da teoria a teoria da mente. Esta concepção-teoria da teoria - poderia descrever todas as tentativas - inclusive míticas - dos seres humanos visando entender o inacessível, ao longo da história.

A importância da metacognição para uma visão renovadora da inteligência é eminentemente psicopedagógica, pois que oferece um excelente instrumento para desenvolver a inteligência, sob vários ângulos. Sempre mais vem se registrando o quanto o uso, mesmo espontâneo, desta atividade, isto é da capacidade de refletir sobre a própria reflexão é um meio poderoso para ampliar e aprofundar a atividade cognitiva de qualquer pessoa, notadamente na infância. É por esta razão que a maior parte das pesquisas sobre metacognição versam sobre este tipo de diagnóstico: averiguar a correlação entre o uso espontâneo da metacognição e o sucesso escolar. No entanto a investigação mais importante e na qual estamos engajados há cerca de duas décadas - é a manipulação da metacognição como variável independente, em pesquisas experimentas, visando obter um salto de escala no desenvolvimento cognitivos de crianças e adolescentes. Neste caminho já conseguimos, reiteradamente, alcançar resultados significativos estatisticamente no desenvolvimento da lógica em crianças pré-operatórias (Seminerio, 1991), bem como do vocabulário e do imaginário. É evidente que nossos experimentos refutam a impossibilidade suposta por Piaget de se obterem esse salto através da comunicação com a criança. Ou seja nossos resultados implicam a possibilidade de promover dialógicamente mudanças na estrutura cognitiva do educando. $\mathrm{O}$ que significa provocar a aprendizagem lato sensu sem esperar a descoberta autônoma e espontânea. É neste pontọ que entendemos a importância do uso da metacognição. Efetivamente pelo método tradicional tal mudança deveria ser impossível: transmitir informações como dados acabados pode ser inócuo. Mas quando se fornecem regras capazes de provocar a reflexão antecipada sobre o pensamento e a conduta, suscitando assim a dedução de condutas produtivas, o salto de escala tem se revelado possível e satisfatório. Coincide aliás esta perspectiva com a de Bandura (1977) que considera a aprendizagem como transmissão de modelos (e, principalmente de metamodelos, diríamos nós, de acordo com a nossa prática de pesquisa).

O esforço que estamos empreendendo por este caminho não tem apenas um objetivo educacional. Visa também contribuir para se elaborarem instrumentos aptos a reduzir as distâncias no 


\section{Franco Lo Presti Seminerio}

desenvolvimento intelectual entre as classes sociais. Estas distâncias perpetuam a iniqüidade de se impor o trabalho penoso - outrora exigido dos escravos aos infradotados, sem qualquer outra compensação. O caminho da emancipação tão claramente enunciado por Habermas (1987) envolve uma marcha lenta mas segura rumo a uma igualdade ideal mas necessária dentro da busca de uma ética universal. A cada um de nós cabe oferecer uma parcela de sua contribuição, convictamente, neste caminho.

\section{Referências Bibliográficas}

Bandura, A.(1977). Social Learning Theory New. Jersey: Englewood Clift

Binet, A. \& Simon, T.H. (1905). Méthodes Nouvelles pour le Diagnostic du niveau intellectuel des

Bruner, J.S. (1948). Perceptual theory and the Rorschach test - J. Pers.17:157-168

Bruner, J.S., Goodnow , J. J. \& Austin G.A. (1956). A Study of Thinking- N York: Wiley

Bruner, J.S. (1973). The Growth of Representational Processes in Childhood - In: Beyond the Information Given- New. York - W.W. Norton \& Co. Inc.

Bruner, J.S. (1991). Le Dévéloppement de l'enfant. Savoir faire Savoir Dire. Paris: P.U.F.

Burt, C. (1949). The Structure of the mind: the results of review of factor analysis. Brit.J. Educ Psych. 1949, 19:100-111.

Burt, C. (1955). Tha evidence for the concept of Intelligence Brit.J. Edc.Psych. (25): 158-177.

Chomsky, N. (1972). I.Q. Tests: Building blocs for new class - Ramparts vol. II n.1.

Davydov, V.V. (1981). Tipos de Generalización en la Enseñanza.La Habana: Pueblo y Educación

Eysenck, H.J. (1971). Raça, Inteligência, Educaçāo - Rio de Janeiro: Eldorado

Eysenck, H.J. \& Kamin, L. (1982). O Grande Debate sobre a Inteligência. Brasília: Ed. da Univ. de Brasília

Fodor, J.A. (1984). Psychosemantics - M.I.T. Press

Fodor, J.A. (1987). The Modularity of Mind. An Essay on Faculty Psychology. M.I.T. Press
Frege, G. (1974). Fundamentos da Aritmética. - Rio de Janeiro: Ed.Abril

Freud, S. (1974). Psicopatologia da vida Cotidiana. In:Edição Standard Brasileira das Obras Completas de S.Freud. Rio de Janeiro, Imago.

Galperin, Ya. (1981). Principales resultados de las investigaciones sobre el problemas de las operaciones mentales de los conceptos. Apud DAVYDOV, V.V. (1981). trad. Tipos de Generalización en la Enseñanzà - La Habana: Pueblo y Educación

Gardner, H. (1995). Inteligências Múltiplas. A teoria na prática. Porto Alegre: Artes Médicas

Gramsci, A (1949). Gli Intellettuali $e$ l'Organizzazine della Cultura - Torino: Einaudi

Guilford, J.P. (1967). The Nature of Human Intelligence- NewYork : Mc Grow-Hill.

Habermas, J. (1987). Théorie de l'Agir communicationnel T.I . Paris: Fayard

Hart. J.T. (1965). Memory and feeling-of- knowing experience Journal of Educational Psychology 56:208-216

Jensen, A.R. (1969). Environment, Heredity and Intelligence. Harvard Reprint Series, $\mathrm{n}^{\circ} 2$

Koriat, A. (1996). Metamemory: the feeling of knowing and its vagaries - in:Sabourin, M. \& al. (org.) Advances in Psychological Science vol. 2 cap. 21 - Anais do XXVI Congresso Internacional de Psicologia -Montréal (Canada)

Leontiev, A.A. (1972) Psicolingiuistica Riuniti: Roma Ed.

Luria, A.R. (1971 ). O cérebro em ação

Miller, G.A. Galanter E. \& Pribram, K (1960) Plans and the Structure of Behavior - New York, Holt

Noël, B. (1992). Metacognition - Bruxelles: De Boeck

Osgood, Ch. (1962). The Measurement of Meaning

Piaget, J. (1947). La Psychologie de l' Intelligence. Paris: A.Colin

Piaget, J. (1957). Epistémologie Génétique et Recherche Psychologique- Paris: P.U.F.

Premack \& Woodruff (1978). Does the chimpanzee have a theory of mind? Behevioral and Brain Sciences 1: 515-526 
Seminerio, F.L.P. (1991). Cognição e Educação - Um projeto de construção teórica Verificações experimentais e Aplicações pedagógicas - Arquivos Bras. de Psicologia 43-3/4: 12-35

Seminerio, F.L.P. (1995). Códigos Morfogenéticos da Cognição - Arquivos Bras. Psic. 47: 3-45

Seminerio, F.L.P. (1996). Piaget - O Constructivismo na Psicologia e na Educação- Rio de Janeiro: Imago Ed.

Seminerio. F.L.P. (1997). Emílio Mira y Lopez-Arquivos Bras. Psic. 47:

Spearman, C. (1904). "General Intelligence" Objectively Determined and Measured". Amer.Jour. of Psychology 15:208-293

Spearman, C. (1927). The Abilities of Man - New York: - Mc Millan.

Spencer, H. (1895). The Principles of Psychology N. York: Appleton

Stern, W. (1971). O Quociente Mental - In: (trad.) Herrnstein,R.J. \& Boring, E.G.- Textos Básicos de História da Psicologia-S. Paulo: Ed. Herder

Sternberg, R. (2000). Psicologia Cognitiva-P. Alegre: Artes Médicas

Thorndike, E.L. (1927). The Measurement of Intelligence - New York: Teachers Coll.

Thurstone, L.L. (1938). Primary Mental Abilities Psychometric Monographs, 1:1-128

Thurstone, L.L. (1948). Psychological Implications of Factor Analysis-Amer.Psychologist, 3: 402408

Varela, F. (1989) Autonomie et Connaissance, Essai sur le Vivant. - Paris. Seuil

Vernon, P.E. (1950) The Structure of Human Abilities - . New. York. Wiley

Vieira, M.A. (1987). Operações formais ápice da ontogênese do pensamento. In: Textos do CPGP $n^{\circ} 8$, Rio de Janeiro: FGV.

Vigotzky, L.S. (1989). A Formação Social da Mente São Paulo: Martins Fontes

Young, M. (1958). The Rise of Meritocracy Baltimore: Penguin. 
176 